\title{
Efficacy of nebulised L-Adrenaline with 3\% hypertonic saline versus normal saline in bronchiolitis.
}

\author{
Shabnam Sharmin ${ }^{1}$, Laila Helaly ${ }^{2}$, Zakir Hossain Sarker ${ }^{3}$, Ruhul Amin ${ }^{4}$, Shafi Ahmed ${ }^{5}$, Sayeda Tabbassum Alam ${ }^{6}$. \\ 'Lecturer, Department of Physiology, Saheed Saurawardy Medical College, Dhaka, ${ }^{2}$ Consultant, Bangladesh Thalassaemia Hospital, ${ }^{3}$ Assistant Professor, Department of Respiratory Medicine, NIDCH, \\ Dhaka, ${ }^{4}$ Professor, Paediatric Pulmonology, Dhaka Shishu Hospital, ${ }^{5}$ Assistant Professor, Department of Paediatrics, Northern International Medical College, ${ }^{6}$ Associate Professor, Department of \\ Paediatrics BSMMU.
}

\begin{abstract}
:
Background: Bronchiolitis is one of the most common respiratory diseases requiring hospitalization. Nebulized epinephrine and salbutamol therapy has been used in different centres with varying results. Objective: The objective of the study was to compare the efficacy of nebulised adrenaline diluted with $3 \%$ hypertonic saline with nebulised adrenaline diluted with normal saline in bronchiolitis. Methods: Fifty three infants and young children with bronchiolitis, age ranging from 2 months to 2 years, presenting in the emergency department of Manikganj Sadar Hospital were enrolled in the study. After initial evaluation, patients were randomized to receive either nebulized adrenaline $1.5 \mathrm{ml}(1.5 \mathrm{mg})$ diluted with $2 \mathrm{ml}$ of $3 \%$ hypertonic saline (group I) or nebulised adrenaline $1.5 \mathrm{ml}(1.5 \mathrm{mg}$ ) diluted with $2 \mathrm{ml}$ of normal saline (group II ). Patients were evaluated again 30 minutes after nebulization. Results: Twenty eight patients in the group I (hypertonic saline) and twenty five in groupII (normal saline) were included in the study. After nebulization, mean respiratory rate decreased from 63.7 to 48.1 ( $\mathrm{p}<.01)$, mean clinical severity score decreased from 8.5 to 3.5 ( $<<.01)$ and mean oxygen saturation increased $94.7 \%$ to $96.9 \%(\mathrm{p}<.01)$ in group I. In group II , mean respiratory rate decreased from 62.4 to 47.4 $(\mathrm{p}<.01)$, mean clinical severity score decreased from 7.2 to $4.1(\mathrm{p}<.01)$ and mean oxygen saturation increased from $94.7 \%$ to $96.7 \%(\mathrm{p}<.01)$. Mean respiratory rate decreased by 16 in group I versus $14.8(\mathrm{p}>.05)$ in group II, mean clinical severity score decreased by 4.6 in group versus $3(\mathrm{p}<.05)$ in group, and mean oxygen saturation increased by $2.2 \%$ and $1.9 \%$ in group and group respectively. Difference in reduction in clinical severity score was statistically significant, though the changes in respiratory rate and oxygen saturation were not statistically significant. Conclusion: The study concluded that both nebulised adrenaline diluted with $3 \%$ hypertonic saline and nebulised adrenaline with normal saline are effective in improving respiratory rate, clinical severity score and oxygen saturation in infants with bronchiolitis; and nebulised adrenaline with hypertonic saline is more effective than nebulised adrenaline with normal saline in improving clinical severity score in bronchiolitis.
\end{abstract}

Key words: Nebulised adrenaline, $3 \%$ hypertonic saline, normal saline, bronchiolitis

[BSMMU J 2014; 7 (1): 15-19]

\section{Introduction:}

Bronchiolitis is the inflammatory disease of the smallest airways and is the leading cause of respiratory distress of small children. ${ }^{1}$ According to a recent survey, bronchiolitis is one of the common respiratory disorders in under five children in Bangladesh and comprises $21 \%$ of all

Address for Correspondence: Dr. Laila Helaly

Consultant, Bangladesh Thalassaemia Hospital Green Garden Tower, Level-6,

25/A and 25/B, Green Road, Dhaka-1205., Mobile: 01711151570 respiratory diseases. ${ }^{2}$ There is no effective and universally accepted treatment of bronchiolitis. ${ }^{3}$ Treatment of bronchiolitis is still mainly supportive. Children with mild bronchiolitis, which form the large majority of cases, are treated at home. Children with moderate and severe distress are hospitalized. ${ }^{3}$ Bronchodilator therapy is not recommended for routine use in the management of bronchiolitis. Review of a few studies shows that nebulised epinephrine has some potential for being efficacious. $^{4}$ 
Hypertonic saline because of physiologic properties can reverse the pathophysiologic effects of bronchiolitis. The pathophysiology of bronchiolitis is an infection of the bronchiolar epithelium with subsequent profound submucosal and adventitial edema, increased secretion of mucus with peribronchiolar mononuclear cell infiltration and epithelial cell necrosis. ${ }^{5}$ Adrenaline, because of its sympathomimetic effect, can decrease the edema of bronchiolar wall and reduce bronchial secretion. ${ }^{6}$ Thus adrenaline may have positive effect in reducing the symptoms of bronchiolitis.

Hypertonic saline may have additive effect in reducing the symptoms of bronchiolitis if combined with adrenaline. If $3 \%$ hypertonic saline is substituted to normal saline in diluting adrenaline for inhalation in patients with bronchiolitis, it may attenuate the bronchial obstruction and thus can decrease the symptoms of bronchiolitis. ${ }^{7}$ We hypothesized simply substituting normal saline solution with hypertonic saline solution in the inhalation mixture for delivering L-adrenaline to infants with bronchiolitis may improve respiratory status and clinical serverity score after inhalation. The study was conducted to evaluate the efficacy of nebulised adrenaline with $3 \%$ hypertonic saline in infants with bronchiolitis so that we can use nebulised $3 \%$ hypertonic saline to get better response.

\section{Methods:}

It was a comparative study. The study was carried out in the emergency and outpatient department of Sadar Hospital of Manikganj which is a one hundred bedded hospital having 20 beds for pediatric patients. About 200 children attend hospital daily seeking medical care. The study was conducted during the period from December 2007 to February 2008. Subjects of moderate \& severe cases of bronchiolitis and age between 2 months to 2 years were included. Subjects of imminent respiratory failure and nebulised adrenaline or salbutamol therapy before attending hospital were excluded. All the parents of the children were given an explanation and about this study.

Clinical severity score ${ }^{8}$

Clinical bronchiolitis severity score is determined from respiratory rate, wheeze, chest indrawing and general examination (Table I).

Table-I

Clinical severity score9

\begin{tabular}{lcccc}
\hline Parameter & \multicolumn{3}{c}{ score } \\
\hline $\begin{array}{l}\text { Respiratory } \\
\text { rate }\end{array}$ & 0 & 1 & 2 & 3 \\
Wheeze & None & $1-45$ & $46-60$ & $>60$ \\
& & $\begin{array}{c}\text { Terminal } \\
\text { expira } \\
\text { tory }\end{array}$ & $\begin{array}{c}\text { Full } \\
\text { expira } \\
\text { tory }\end{array}$ & $\begin{array}{c}\text { Inspiratory } \\
\text { and } \\
\text { expiratory }\end{array}$ \\
$\begin{array}{lcccc}\text { Retraction } \\
\text { Intercostal } \\
\text { only }\end{array}$ & $\begin{array}{c}\text { Trach } \\
\text { eosternal }\end{array}$ & $\begin{array}{c}\text { Severe } \\
\text { with nasal } \\
\text { flaring }\end{array}$ \\
General & Normal & & & Irritable, \\
condition & & & & lethargic, \\
& & & & poor \\
& & & & feeding \\
\hline
\end{tabular}

Severity of bronchiolitis ${ }^{10}$ :

Mild: normal feeding, normal respiratory rate,mild or no chest indrawing.

Moderate: tachypnea,moderate chest indrawing, wheeze.nasal flaring,may appear short of breath when feeding.

Severe: unable to feed,severe respiratory distress with marked chest indrawing, cyanosis may be present.

On arrival of suspected cases of bronchiolitis, history was taken carefully and thorough physical examination was done. Selected patients were monitored for oxygen saturation; $\mathrm{x}$-ray chest was done to exclude pneumonia or tuberculosis. Clinical severity of bronchiolitis and clinical bronchiolitis score was determined. Demographic characteristics and baseline clinical characteristics such as general condition, respiratory rate, wheeze, chest indrawing, oxygen saturation, clinical severity and clinical bronchiolitis score were recorded in the pre-tested questionnaire. The patients were then randomly allocated into group I and group II. Randomization was done by lottery method. Informed consent was taken from the parents. Patients in group I were treated with single dose of nebulised adrenaline (1:1000) $1.5 \mathrm{ml}(1.5 \mathrm{mg})$ diluted 
with $2 \mathrm{ml}$ of $3 \%$ hypertonic saline whereas patients in group II were treated with single dose of nebulised adrenaline (1:1000) $1.5 \mathrm{ml}(1.5 \mathrm{mg})$ diluted with $2 \mathrm{ml}$ of normal saline. Nebulisation was done by jet nebuliser and was administered by using face mask. Humidified oxygen $2 \mathrm{~L} / \mathrm{min}$ was provided to all patients in both groups when oxygen saturation was less than $93 \%$.

All the patients were evaluated 30 minutes after nebulisation. Changes in the clinical characteristics, clinical severity score and oxygen saturation were noted. The decision for further management was taken on the basis of this evaluation. Patients who improved (decrease in respiratory rate and wheezing, normal feeding, improvement in general condition) were discharged with advice of further nebulisation for 3-5 days). Patients who did not improve were admitted in the hospital under supervision of consultant of pediatric unit. Data were expressed as mean \pm SD. Statistical analysis was done by paired t-test.

\section{Results:}

Fifty three previously healthy infants with bronchiolitis were enrolled in the study- 28 in the group I (adrenaline with hypertonic saline) and 25 in the group II (adrenaline with normal saline). Seventeen were male and 11 female in group I, and 16 male and 9 female in group II. Mean age was $4.5 \pm 1.9$ and $5.1 \pm 2.0$ months in group I and II respectively. Mean weight was $5.8 \pm 1.2 \mathrm{~kg}$ in group I and $6.0 \pm 1.3 \mathrm{~kg}$ in group II (Table II).

\section{Table-II}

Demographic characteristics of group I and group II

\begin{tabular}{lcc}
\hline $\begin{array}{c}\text { Demographic } \\
\text { characteristics }\end{array}$ & $\begin{array}{c}\text { Group I } \\
\text { (Adrenaline with } \\
\text { hypertonic saline) } \\
\mathrm{n}=28\end{array}$ & $\begin{array}{c}\text { Group II } \\
\text { (Adrenaline with } \\
\text { normal saline) } \\
\mathrm{n}=25\end{array}$ \\
\hline $\begin{array}{l}\text { Age (months): } \\
\text { Mean } \pm \text { SD }\end{array}$ & $4.5 \pm 1.9$ & $5.1 \pm 2.0$ \\
Sex & & \\
$\quad$ Male & 17 & 16 \\
$\quad$ Female & 11 & 9 \\
Weight $(\mathrm{kg})$ & &
\end{tabular}

Mean \pm SD

$5.8 \pm 1.2$

$6.0 \pm 1.3$

Baseline clinical parameters were respiratory rate (mean \pm SD) $63.7 \pm 7.4$ versus $62.4 \pm 8.0$, clinical severity score (mean \pm SD) $8.5 \pm 2.1$ versus $7.2 \pm 2.3$, oxygen saturation (mean $\pm \mathrm{SD}$ ) $94.7 \pm 2.0 \%$, heart rate (mean $\pm \mathrm{SD}) 149.1 \pm$ 10.4 versus $143.6 \pm 13.4$ in group I and group II respectively (Table III).

\section{Table-III}

Clinical parameters in group I before and after nebulisation (adrenaline with 3\% hypertonic saline)

\begin{tabular}{|c|c|c|c|}
\hline \multirow[t]{3}{*}{ Clinical parameters } & Before & After & \multirow{2}{*}{ P value } \\
\hline & \multicolumn{2}{|c|}{ Nebulisation Nebulisation } & \\
\hline & Mean \pm SD & Mean \pm SD & \\
\hline Respiratory rate & $63.7 \pm 7.4$ & $48.1 \pm 9.7$ & $<.01$ \\
\hline Clinical severity score & $8.5 \pm 2.1$ & $3.5 \pm 2.0$ & $<.01$ \\
\hline Oxygen saturation (\%) & $94.7 \pm 1.5$ & $96.9 \pm 1.0$ & $<.01$ \\
\hline Heart rate & $149.1 \pm 10.4$ & $143.6 \pm 13.4$ & $>.05$ \\
\hline
\end{tabular}

Respiratory rate and clinical score decreased and oxygen saturation increased significantly with nebulisation.

Table-IV

Clinical parameters in group II before and after nebulisation (nebulised adrenaline with normal saline)

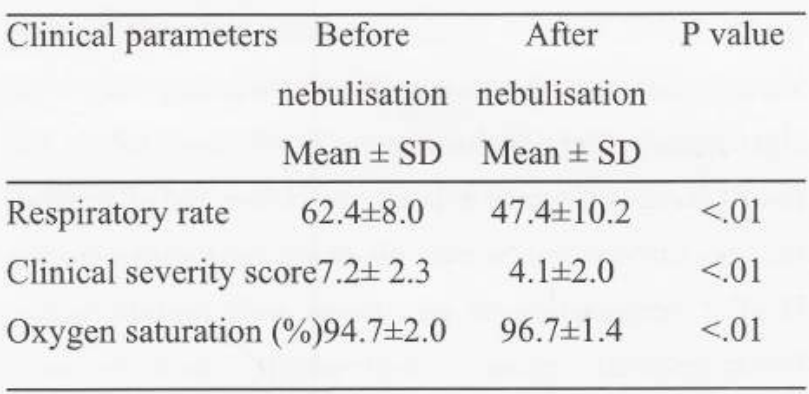

Respiratory rate and clinical score decreased and oxygen saturation increased significantly with nebulisation.

After nebulisation, mean respiratory rate decreased by 16.0 \pm 9.8 in group $\mathrm{I}$ in comparison to $14.8 \pm 10.2$ in group II $(p>05)$. Mean clinical severity score decreased by $4.6 \pm 2.4$ in group I against $3.0 \pm 2.1$ in group $\mathrm{II}(\mathrm{p}<.05)$. Mean oxygen saturation increased by $2.2 \pm 1.4 \%$ in group I compared with $2.0 \pm 1.7 \%$ in group II $(\mathrm{p}>.05)$ [ Table V] 
Table-V

Comparison of response between group I and group II

(adrenaline with Hypertonic saline versus adrenaline with normal saline)

\begin{tabular}{lccc}
\hline Responses & $\begin{array}{c}\text { Group I } \\
\text { (Adr+3\% HS)* }\end{array}$ & $\begin{array}{c}\text { Group II } \\
\text { Mean } \pm \text { SD }\end{array}$ & P value \\
& Mean \pm SD & \\
\hline $\begin{array}{l}\text { Mean decrease } \\
\text { in respiratory rate }\end{array}$ & $16.0 \pm 9.8$ & $14.8 \pm 10.2$ & $>.05$ \\
$\begin{array}{l}\text { Mean decrease } \\
\text { in Clinical score }\end{array}$ & $4.6 \pm 2.4$ & $3.0 \pm 2.1$ & $<.05$ \\
$\begin{array}{l}\text { Mean increase in } \\
\text { Oxygen saturation }\end{array}$ & & & \\
(\%) & & & \\
\hline
\end{tabular}

*Adr- adrenaline, HS- hypertonic saline, NS- normal saline

\section{Discussion:}

There was no significant difference in age,sex and weight in two groups. All the parameters improved significantly in both the groups after nebulisation therapy with either form of adrenaline. After nebulisation with adrenaline with $3 \%$ hypertonic saline, mean respiratory rate and mean clinical severity score decreased and mean oxygen saturation increased ; all respiratory parameter improved significantly after nebulisation with hypertonic saline, but there was no difference in heart rate before and after nebulisation. Similar results were observed in patients of group II after nebulisation of adrenaline with normal saline. Mean respirator mean clinical severity score deceased and mean oxygen saturation increased. All the respiratory parameters improved significantly after nebulisation of adrenaline with normal saline. Several studies have been conducted in different centers to evaluate the efficacy of nebulised adrenaline in infants and children with bronchiolitis. ${ }^{3,67}$

Mandelberg et al conducted a study in hospitalized infants with bronchiolitis and observed that nebulised adrenaline with 3\% hypertonic saline produced better responses than adrenaline with normal saline in improving the clinical severity score than adrenaline with normal saline. ${ }^{11}$

In another study, Sarrel et al found terbutaline with $3 \%$ hypertonicl salinewas more effective than terbutaline with normal saline in decreasing the clinical severity score in hospitalized infants with bronchiolitis. ${ }^{8}$

Tal et al evaluated the efficacy of nebulised adrenaline with hypertonic saline in ambulatory patients with bronchiolitis and found hypertonic saline produced better response than normal saline particularly in decreasing hospital admission and decreasing the symptoms of

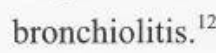

This study demonstrated better efficacy of nebulised adrenaline with $3 \%$ hypertonic saline than adrenaline with normal saline in improving the symptoms, particularly in decreasing the clinical severity score of bronchiolitis. The study was conducted in patients presenting in the emergency and out-patient department. Diagnosis of bronchiolitis was made on clinical grounds only; RSV detection was not possible because of economic constraints. Role of nebulised adrenaline with hypertonic saline in reducing the duration of illness and its role in reducing the duration of hospital stay was beyond the scope of the study. No adverse effect was noted in the study. Heart rate did not change significantly after nebulisation with adrenaline. Arrhythmia was noted in none of the patients.

\section{Conclusion:}

The study concludes that both nebulised adrenaline diluted with $3 \%$ hypertonic saline and nebulised adrenaline diluted with normal saline are effective as a short term therapy in decreasing the respiratory rate, clinical severity score, and improving the oxygen saturation in infants with bronchiolitis. Nebulised adrenaline diluted with $3 \%$ hypertonic saline is more effective than nebulised adrenaline diluted with normal saline particularly in improving 


\section{the clinical severity score in bronchiolitis.}

\section{References :}

1. Kabir ARML, Amin MR,Bronchiolitis: An update. Bangladesh $\mathbf{J}$ Child Health 2002; 22: 22-24.

2. Parrot RH, Kim HW, Arrobio JO. Epidemiology of respiratory syncytial virus infection in Washington, DC. Infection and diease associated with respect toage, immunologic status, race and sex. AMJ L Epidemiology 1973; 98: 289-300.

3. Harting L, Weibe N, Russel K. Meta-analysis of randomized controlled trials evaluating the efficacy of epinephrine for the treatment of acute viral bronchiolitis. Arch Pediatr Adolesc Med 2003; 157:957-964.

4. Kaassen TP, Sutcliffe T, Watters LK 6neak et al. Dexamethsone in salbutamol-treated patients with bronchiolitis. J pediatr 1997; 130: 170-172.

5. Sethi GR, Gaurav N. Evidence based treatment of bronchiolitis. Ind J Pediatr 2004; 71: 733-737.

6. Bertrand P, Aranibar H, Castro E, sanchez I. Efficacy of nebulised epinephrine versus salbutamol in hospitalized infants with bronchiolitis. Pediatr Pulmnol 2001; 31: 284-8.

7. Agency for Healthcare and quality. Management of Bronchiolitis in infants and children. Evidence report/Technology assessment No. 69. Rockville, MD: Agency for Healthcare Research and Quality; 2003. AHRQ Publication No. 03-E014.

8. Sarrel EM, Tal G, Someck E. Nebulised 3\% hypertonic saline solution treatment in ambulatory children with viral bronchiolities decreases symptoms. Chest 2002; 122: 2015-2020

9. Kristjansson S, Lerdup Carisen, Wennergren G. Nebulised racemic adrenaline in the trKristjansson S, Lordup Carisen, Wennergren G. Nebulised racemic adrenaline in the treatment of bronchiolitis in infants and toddlers. Arch Dis Child. 1993;69: $650-654$

10. Dominic AF, Henry AK. Bronchiolitis: assessment and evidencebased management. MJA 2004; 180:399-404.

11. Mandelberg A, Tal G, Witzling M. Nebulised 3\% hypertonic saline solution in hospitalized infants with viral bronchiolitis. Chest 2003; 123:481-487

12. Tal G, Cesar K, Oron A. hypertonic saline/ epinephrine treatment in hospitalized infants with viral bronchiolitis reduces hospitalization stay: 2 years experience. IMAJ 2006; 8: 169-173. 